\title{
Principal Component
}

National Cancer Institute

\section{Source}

National Cancer Institute. Principal Component. NCI Thesaurus. Code C60694.

One of the axes representing the projection of varience resulting from principal component analysis. 